EESTI NSV TEADUSTE AKADEEMIA TOIMETISED. 20. KÖIDE KEEMIA * GEOLOOGIA. 1971. NR. 1

ИЗВЕСТИЯ АКАДЕМИИ НАУК ЭСТОНСКОИ ССР. ТОМ 20

ХИМИЯ * ГЕОЛОГИЯ. 1971, № 1

удк 543.276

A. ИВАНОВ, О. ЭЙЗЕН, AHНЕ OPAВ

\title{
К ВОПРОСУ ОБ ОПРЕДЕЛЕНИИ ИНДЕКСОВ УДЕРЖИВАНИЯ
}

A. IVANOV, O. EISEN, ANNE ORAV. VALLJUMISINDEKSITE MÄARAMISEST

A.IWANOW, O. EISEN, ANNE ORAV. OBER DIE BESTIMMUNG DER RETENTIONSINDICES

За последнее время опубликовано большое количество работ [1-6], в которых для качественной интерпретации хроматограмм использовались индексы удерживания или обсуждались возможности их применения.

Известно, что индексы удерживания вычисляются по формуле [7]:

$$
I_{x}=100 n \frac{\lg R_{x}-\lg R_{N}}{\lg K_{N+n}-\lg R_{N}}+100 N,
$$

где $R_{x}, R_{N}$ и $R_{N+n}-$ приведенные параметры удерживания искомого компонента и $н$-алканов, принятые за стандарты, с числом углеродных атомов $N$ и $N+n$. При расчете индексов необходимо выполнение условия $R_{N}<R_{x}<R_{N+n}$, хотя в ряде случаев и допускается некоторая экстраполяция. В рекомендациях Комитета по вопросам представления данных в газовой хроматографии [8] считается обязательным применение $\boldsymbol{\mu}$-алканов в качестве стандартов. Однако последнее условие значительно увеличивает затрачиваемое на анализ сложных многокомпонентных смесей время, особенно на капиллярных колонках, так как для полной качественной и количественной интерпретации необходимо дублирование анализов с чистой смесью и с добавкой н-алканов.

Ниже представлены результаты работы по расчету индексов удерживания без применения $\mathrm{H}$-алканов. Анализировалась фракция сланцевой смолы грузинского липтобиолита, выкипающая в пределах $150-200^{\circ} \mathrm{C}$ и содержащая 69 компонентов. Хроматограмма смеси получена на хроматографе типа Chrom-2 с капиллярной колонкой (80 м, полиэтиленгликоль $4000,91^{\circ}, \mathrm{N}_{2}$ ). Время, затрачиваемое на один анализ, составляло 6 ч.

Получение окончательных результатов в случае повторных анализов затягивается не только за счет чистого хроматографирования, но и за счет дополнительных измерений и расчетов хроматограмм.

Расчет показал, что для определения индексов удерживания неизвестных компонентов можно применять не только $H$-алканы, но и любые другие компоненты, индексы которых в данных условиях хроматографирования известны. В таком случае формула (1) приобретает более общий вид:

$$
I_{x}=\left(I_{2}-I_{1}\right) \frac{\lg R_{x}-\lg R_{1}}{\lg K_{2}-\lg R_{1}}+i_{1}
$$


где $I_{x}, I_{1}$ и $I_{2}-$ индексы удерживания искомого и двух любых известных компонентов, принимаемых за стандарты; $R_{x}, R_{1}$ и $R_{2}$ соответствующие приведенные параметры удерживания.

Следует особенно подчеркнуть равенство значений величины $b^{\prime}$

$$
b^{\prime}=\frac{100 n}{\lg R_{N+n}+\lg R_{N}}=\frac{I_{2}-I_{1}}{\lg K_{2}-\lg R_{1}} \approx \text { const }
$$

в формулах (1) и (2), а также независимость этой величины от выбора стандартов, что во втором случае особенно важно.

Большие колебания значения $b^{\prime}$ свидетельствуют о наличии значительной флуктуации условнй хроматографирования и о вытекающем из этого следствии - нарушении линейности зависимости $\lg R_{N}$ от числа углеродных атомов $н$-алканов, что, как известно, является основой применения системы индексов удерживания [].

Для иллюстрации сказанного в таблице приведены результаты расчета индекса удерживания бензола с использованием в качестве стандартных веществ как н-алканов (формула (1)), так и ряда других компонентов, присутствующих в смеси (формула (2)). Приведены также значения $b^{\prime}$ для каждого случая.

Полученные данные подтверждают применимость формулы (2), открывающей более широкие возможности расчета индексов удерживания, а также указывают на достаточно широкие возможности экстраполяцин при расчетах.

Результаты расчета $I_{\text {бензол }}$ по формуле (2) $\left(\lg R_{\text {бензол }}=2,0569\right)$

\begin{tabular}{|c|c|c|c|c|c|c|c|c|}
\hline $\begin{array}{l}\text { Поряд- } \\
\text { ковый } \\
\text { номер } \\
\text { стан- } \\
\text { дарта } 1\end{array}$ & $\lg R_{1}$ & $I_{1}$ & $\begin{array}{l}\text { Поряд- } \\
\text { ковый } \\
\text { номер } \\
\text { стан- } \\
\text { дарта 2 }\end{array}$ & $\lg R_{2}$ & $I_{2}$ & $b^{\prime}$ & 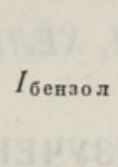 & $\begin{array}{c}\text { Откло- } \\
\text { нение от } \\
I_{\text {бензолл }}= \\
=961,7\end{array}$ \\
\hline $\begin{array}{l}6 \text { (н-нонан) } \\
0 \text { (н-октан) } \\
6 \\
3 \\
4\end{array}$ & $\begin{array}{l}1,8976 \\
1,6385 \\
1,3222 \\
1,8228 \\
2,3273\end{array}$ & $\begin{array}{c}900 \\
800 \\
673,3 \\
871,5 \\
1066,6\end{array}$ & $\begin{array}{l}27 \text { (н-декан) } \\
33 \text { (толуол) } \\
31 \text { (децен-1) } \\
45 \\
54\end{array}$ & $\begin{array}{l}2,1553 \\
2,3139 \\
2,2765 \\
2,5827 \\
2,8825\end{array}$ & $\begin{array}{l}1000 \\
1061,5 \\
1047 \\
1165,6 \\
1282,3\end{array}$ & $\begin{array}{l}387 \\
386,5 \\
392 \\
388 \\
387,5\end{array}$ & $\begin{array}{l}961,7 \\
961,8 \\
961,3 \\
962,4 \\
961,6\end{array}$ & $\begin{array}{r}0,0 \\
+0,1 \\
-0,4 \\
+0,7 \\
-0,1\end{array}$ \\
\hline
\end{tabular}

Линейность зависимости $I=\varphi(\lg R)$ указывает на возможность графического определения индексов. Применение при этом полулогарифмического масштаба значительно упрощает графический метод, так как исключает необходимость логарифмирования.

Преимущество описанного метода в том, что часто при анализе сложных многокомпонентных смесей некоторые компоненты уже известны. В то же время добавка стандартных веществ может изменить время удерживания отдельных компонентов, влияя тем самым на результаты определения. Определение же индексов на основании параллельной хроматограммы смеси $H$-алканов так же может оказаться не достаточно точным.

\section{ЛИТЕРА Т Р А}

1. Кейко В. В., Прокопьев Б. В., Кузменко Л. П., Калинина Н. А., Гуса ро в А. В., Т р о фи м о в Б. А., Изв. АН СССР. Сер. хкм., № 4, 755 (1969).

2. D o u g l a s A. G., J. Chromatogr. Sci., 7, 582 (1969).

3. Ю фит С. С., Руденко Б. А., К Ра сн а Ж. А., Докл. АН СССР, 188, 156 (1969). 
4. Березкин В. Г., С ах аров В. М., Анв а ер Б. И., Заводск. лаборатория, 32, 669 (1966).

5. K r u p č i k J., L i ška O., S i n g li a r M., Chromatographia, 2, 393 (1969).

6. S chomburg G., Cromatographia, 2, 431 (1969).

7. Kov at s E., Helv. Chim. Acta, 41, 1915 (1958).

8. E t t r e L. S., Analyt. Chem., 36, 31A (1964).

9. Rohrschneider L., Chromatographia, 2, 437 (1969).

$\begin{array}{cc}\text { Институт химии } & \text { Поступила в редакцию } \\ \text { Академии наук Эстонской ССР } & 8 / \mathrm{X} 1970\end{array}$

EESTI NSV TEADUSTE AKADEEMIA TOIMETISED. 20. KOIDE

KEEMIA * GEOLOOGIA. 1971, NR. 1

ИЗВЕСТИЯ АКАДЕМИИ НАУК ЭСТОНСКОЙ ССР. ТОМ 20

Химия * ГЕОЛОГИя. 1971, № 1

удК $541.12 .034 .0^{\circ}$

О. ЭИЗЕН, ХЕЛЬЮ РАУДЕ, РЕЕТ ВННРЕС, Х. КНППЕР

\section{ИЗУЧЕНИЕ СОСТАВА ЛЕТУЧИХ КОМПОНЕНТОВ РЯБИНОВОГО ВИНА МЕТОДОМ ГАЗОВОЙ ХРОМАТОГРАФИИ}

O. EISEN, HELJU RAUDE, REET VIIRES, H. KIPPER. PIHLAKAMARJAVEINIS SISALDUVATE LENDUVATE UHENDITE KOOSTISE UURIMINE GAASIKROMATOGRAAFILISEL MEETODIL.

O. EISEN, HELJU RAUDE, REET VIIRES, H. KIPPER. INVESTIGATION OF THE COMPOSITION OF THE VOLATILE COMPOUNDS OF ASHBERRY WINE BY GAS CHROMATOGRAPHY

Объектом данного исследования служили рябиновые вина Валгаского винного завода разной выдержки, изготовленные в 1967 и 1969 гг. Анализировались четыре пробы вина: 1967 г., 1969 г., 1969 г., выдержанное при $50-54^{\circ} \mathrm{C}$ в течение месяца с аэрацией, и 1969 г., выдержанное при $50-54^{\circ}$ в течение месяца без аэрации.

Пробы экстрагировались в делительной воронке смесью пентана с диэтиловым эфиром $(9: 1)$ ['] или только диэтиловым эфиром. После отгонки основной части растворителей экстракты подвергались газохроматографическому анализу на аппарате «Хром-3», снабженном пламенно-ионизационным детектором. Для газохроматографического анализа использовалась колонка из медной трубки длиной $6 \mu$ и внутренним диаметром 4 мм, заполненная полиэтиленгликолем 4000 (15\%) на хромосорбе $W$ 60-80 меш. Газом-носителем служил азот со скоростью $25 \mathrm{~cm}^{3} /$ мин. Температура колонки $85^{\circ}$. Результаты анализа приведены в табл. 1 н 2. 